\title{
Optimization of Construction Process of Double Side Slope Method Used in Super Section Tunnel
}

\author{
Xingliang Jin ${ }^{1, a}$, Bin Liang ${ }^{1, b}$ \\ Civil Engineering School, Henan University of Science and Technology, Luoyang 471023, China \\ a1278461291@qq.com, lliangbin4231@163.com
}

\begin{abstract}
Keywords: shallow buried super section flat tunnel; surrounding rock stress; double side slope method; excavation step sequence optimization

Abstract. Taking Chongqing Metro Line 5 tunnel project as an engineering example, which is a shallow buried large section tunnel. The finite element numerical analysis software MIDAS-GTS was used to establish the three-dimensional finite element model of the tunnel. The analysis data was compared with the site monitoring data. The results show that the mechanical indexes of the super large cross section tunnel increase suddenly when the middle wall core soil were removed. This stage should strengthen the monitoring frequency. The data of ground surface settlement, vault settlement and the level convergence under three kinds of excavation step were compared. In the end, it was concluded that the " $L$ " type excavation step is reasonable which the construction efficiency is increased and the construction cost is saved. This paper puts forward the reasonable steps of the construction of large span flat tunnel under the geological conditions of the project.
\end{abstract}

\section{Introduction}

The construction of shallow buried large section tunnel is prone to accidents under the condition of poor stability of surrounding rock. The double side drift method is used widely as it can effectively control the ground settlement and maintain the stability of tunnel face [1]. The excavation section partition and construction step is more than other and the cross section can't be closure timely using the double side slope method. Therefore, it is of great significance to accelerate the construction efficiency under the premise of ensuring safety and quality [2,3].

The domestic and foreign scholars mainly use the method of combining theory and numerical analysis on the study of the key technical issues for the construction of the double side slope method [4]. In this paper, the dynamic simulation of the tunnel construction process was established by using the numerical analysis software. The ground settlement, vertical displacement of the surrounding rock, the lateral deformation of the tunnel was calculated, and the mechanical characteristics of surrounding rock and spray mixed support were analyzed. The original design construction step was adjusted. The numerical models were established under three kinds of construction step. The stability of surrounding rock during tunnel construction was analyzed, and the numerical analysis data was compared with the field measured data. The optimized construction step was obtained.

\section{Project Profile}

The tunnel of line No. 5 of Chongqing Metro is a single arch tunnel with four lines. The maximum height of the tunnel excavation space nearly $17.2 \mathrm{~m}$, span is $27.6 \mathrm{~m}$ and the total excavation area is $388.47 \mathrm{~m} 2$, flat rate close to 0.62 . The thickness of tunnel roof rock is $16.2 \sim 20.7 \mathrm{~m}$. The main site of groundwater is perched and weathering of bedrock fissure water. The field outcrop stratum 
consists of sandy mudstone, the quality grade is IV. It was constructed by the method of symmetrical excavation step sequence of double side slope method according to the design of large cross section tunnel interval.

\section{Finite Element Model}

Model parameters. The tunnel surrounding rock constitutive model is Mohr-coulomb model. The linear elastic model used in bolt, steel and concrete. Three-dimensional solid element was used in surrounding rock. Specific parameters are shown in Tab.1 below.

Tab.1 Basic mechanical parameters of tunnel surrounding rock and structural material
\begin{tabular}{|c|c|c|c|c|c|c|}
\hline \multirow{2}{*}{ Type } & $E / \mathrm{MPa}$ & $\gamma / \mathrm{kN} / \mathrm{m}^{3}$ & $C / \mathrm{MPa}$ & $\varphi /{ }^{\circ}$ & $\mu$ & \multirow{2}{*}{ Constitutive model } \\
\hline Sandy mudstone & 1660 & 25.6 & 0.75 & 33.3 & 0.36 & Mohr-coulomb \\
\hline Sprayed concrete & 28000 & 23 & $/$ & $/$ & 0.2 & Linear elasticity \\
\hline Bolt & 200000 & 78 & $/$ & $/$ & 0.3 & Linear elasticity \\
\hline Lining & 33500 & 25 & $/$ & $/$ & 0.2 & Linear elasticity \\
\hline
\end{tabular}

Boundary condition. The horizontal direction of the left and right boundaries of the model was constrained. The top was a free boundary. The vertical and horizontal directions of the bottom boundaries were constrained.

Finite element model. According to the finite boundary and finite element analysis theory and combined with practical engineering, the calculation model of surrounding rock on both sides with 2 times of the diameter of the tunnel surrounding rock bottom width, 2 times of the diameter of the tunnel as finite element analysis, the tunnel depth is $50 \mathrm{~m}$. Fig. 1 shows the finite element model.

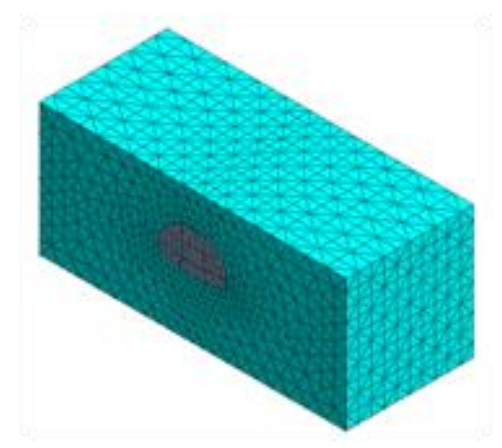

Fig.1 Finite element model

\section{Calculation Results and Analysis}

Variation of settlement and convergence value of different excavation steps with construction step. It can be seen from Fig.2 that the ground settlement value curve of the three kinds of excavation process has a sudden change when the middle wall core soil was removed. This is due to the loss of the support to the top of the tunnel after the middle wall core soil removal. Unilateral excavation method and symmetrical excavation method changes were basically the same. The final ground settlement of unilateral excavation was $4.33 \mathrm{~mm}$. The final ground settlement of symmetric excavation was $4.32 \mathrm{~mm}$. The ground settlement of " $\mathrm{L}$ " shaped excavation process was $5.47 \mathrm{~mm}$.

It can be seen from Fig.3 that the change rule of vault settlement of the three excavation process with the construction was in good agreement. The arch crown settlement of the unilateral 
excavation method was $8.75 \mathrm{~mm}$. The arch crown settlement of the symmetrical excavation method was $8.64 \mathrm{~mm}$. The "L" shape excavation method was smaller than the first two working conditions which was $7.48 \mathrm{~mm}$.

Fig. 4 reflected the three excavation process of foot horizontal convergence value changes with the construction step. The foot horizontal convergence value presents four steps. The first step changes when one side heading through. The second step changes when another heading through. The third step appeared when the middle wall core soil removal. The fourth step appeared after the tunnel through.

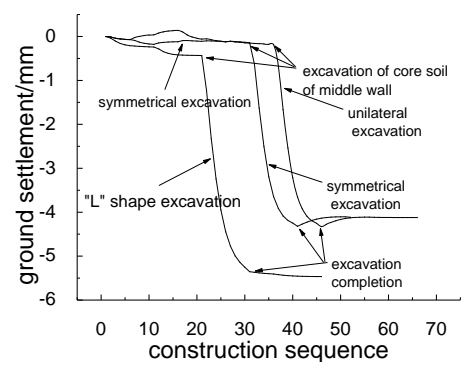

Fig. 2 Surface subsidence

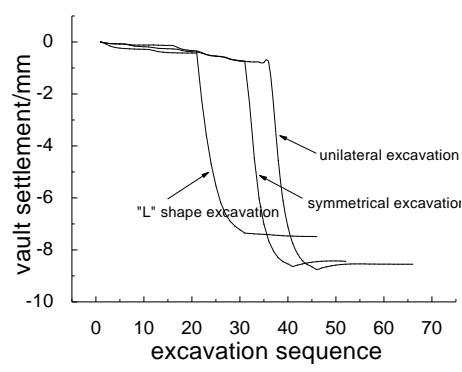

Fig.3 Vault settlement

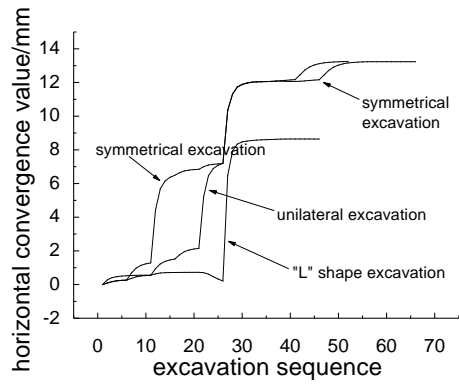

Fig. 4 Horizontal convergence of arch foot

Variation law of surrounding rock stress with construction step in different excavation procedure. It can be seen from Fig.5 that the equivalent stress of the surrounding rock in the construction process of the symmetrical excavation method was stable. The effective stress of the surrounding rock of the single side excavation and the " $\mathrm{L}$ " shape excavation changed. The mutation appeared in tunnel working face. Due to the middle wall core soil was removed. The surrounding rock stress was released in working face. As the whole, the stress of surrounding rock in the single side excavation method and the "L" shape excavation method was smaller than that of the symmetric excavation method. The ultimate stress stability value of surrounding rock was small of both.

It can be seen from Fig.6 that the effective stress in arch lumbar appeared two mutations. The first mutation was due to the excavation of two heading. The second mutation was due to the loss of the middle wall was removed. The stress of arch lumbar was basically the same under three kinds of excavation method. The surrounding rock in arch lumbar was subjected high stress when lost the support of middle wall core soil. The stress of the surrounding rock in arch lumbar of the construction method of "L" shape was smaller than other two, which indicates that "L" shape excavation construction method has some advantages in this project.

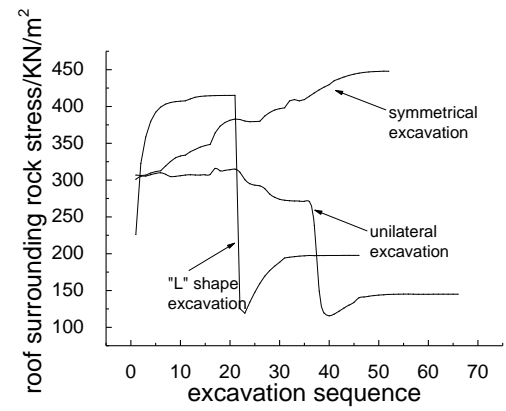

Fig. 5 Effective stress of arch crown rock

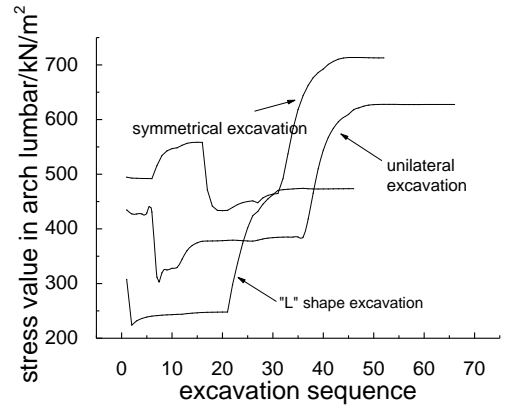

Fig. 6 Effective stress of surrounding rock in arch lumbar

Comparative analysis of numerical calculation and monitoring data. It can be seen from Fig.7 8 that the horizontal convergence calculated values agree well with the measured values. The ground settlement data was bigger than the numerical simulation data. The reason maybe: (1) the original surface landform of the tunnel belongs to tectonic denudation hills. It was used the city 
main road after the artificial transformation. There were artificial fill. The actual settlement value was larger than the numerical value under the action of rain. (2) The site construction conditions were complicated. The bleating excavation had some disturbance to surrounding rock. (3) There were more rain and groundwater in Chongqing area, which had some influence on the stability of tunnel surrounding rock. (4) The construction process of double side slope method is complex. The cross section can't be closed in time.

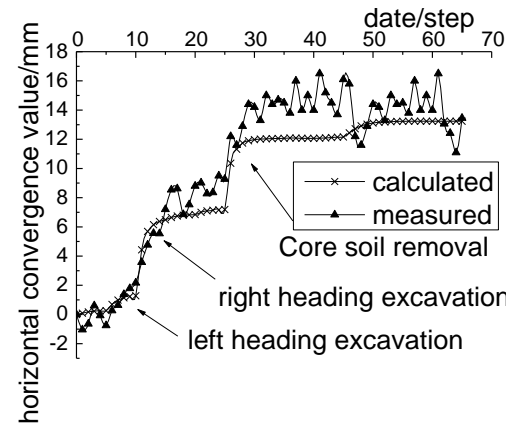

Fig. 7 Horizontal convergence

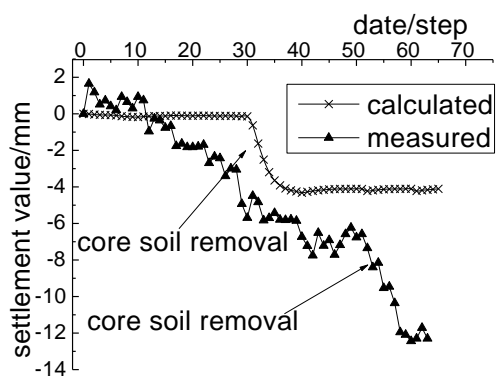

Fig. 8 ground settlement

\section{Conclusions}

The finite element numerical analysis software MIDAS-GTS was used to establish the three-dimensional finite element model of the tunnel. The calculated data was compared with the field measured data. The numerical result was basically consistent with the measured data, and the numerical simulation was reasonable and can be used as reference for similar projects.

The value of ground settlement, vault settlement and arch foot horizontal convergence will be a catastrophe when the middle wall core soil removal in the process of tunnel excavation. In this stage should strengthen the monitoring frequency, pay close attention to the change of control indicators, and to ensure the safety of construction.

Comprehensive consideration, "L" shape excavation's excavation step was less, and can effectively shorten the construction cycle, reduce construction costs which under the premise of ensuring quality and safety. Finally, it was determined that the "L" shape excavation process adjustment scheme was optimal.

\section{References}

[1] B.S. Guan, Deformation of tunnels with soft surrounding rocks and its control, J. Tunnel Construction. 1 (2011)1-17.(in Chinese)

[2] F. Gao, X. K. Tan, Stability analysis on large section tunnel with double side drift method, J. Journal of Chongqing Jiaotong university(natural science). 3 (2010)363-440. (in Chinese)

[3] J. Guo, Analysis on construction safety of optimized double side drift method, J. Tunnel Construction. 6 (2014) 526-533. (in Chinese)

[4] X. Li, C. He, P. Geng, J.L. Ding, Construction schemes and supports mechanical characteristics of shallow embedded large section tunnel, J. Journal of central south university(Science and Technology). 9 (2015) 3386-3394. (in Chinese) 